\title{
Unas lecciones de metafísica de Ortega y Gasset
}

El presente trabajo tiene por objeto exponer algunos elementos claves en la filosofía de Ortega, con el fin de abonar al reconocimiento de su obra e insistir en la importancia que su producción filosófica ha tenido tanto en la historia de la filosofía como en la filosofía primera de Zubiri en concreto. Para tal propósito presentamos este artículo que se divide en cuatro apartados: una breve reseña biográfica; un resumen de su libro Unas Lecciones de metafísica; un comentario a los contenidos de ese libro que, retomando aportes de Antonio González y Jordi Corominas, pretende ubicar el planteamiento orteguiano temática y temporalmente y evidenciar sus fortalezas y debilidades; y, finalmente, una conclusión.

\section{Vida de Ortega}

Lo más sorprendente de la vida de Ortega y Gasset es la popularidad que lo caracterizó y que continúa caracterizándolo aun ahora, transcurridos ya 44 años desde su muerte. Básicamente, dos cosas hicieron de Ortega un personaje más polémico de lo que suele ser dado a un filósofo: su activismo político-que lo llevó incluso a diputado, entre otras faenas militantes-y su profundo interés en hacer de la filosofía un saber accesible al gran público español. De lo primero - sumado, claro está, a su declarado ateísmo-, Ortega logró la hostilidad del régimen franquista en vida y el odio de los tardíos detractores de Franco después de muerto. De lo segundo, que es sin duda lo importante, queda el legado de un hombre cuya consagración a la vida intelectual no impidió su vínculo estrecho con la España pública, una España de la que él se sentía producto y deudor.

Ortega nace en 1883, en Madrid, en el seno de una familia burguesa ilustrada -propietaria del periódico madrileño El Imparcial- Cursa su bachillerato en el colegio de los jesuitas en Málaga, inicia sus estudios de filosofía en la Universidad de Deusto y, poco después, los continúa en la Universidad Central de Madrid, de donde obtiene también su doctorado. Desde entonces sus preocu- 
paciones intelectuales empezaron a girar en torno al problema de España. Su idea era que la débil situación española podía ser superada gracias a una vanguardia intelectual que se encargara de educar a las masas, valiéndose de los elementos de la cultura europea. En el marco de esa preocupación cabe situar el viaje de estudios que, finalizado el doctorado en filosofía, hace a Alemania. Visita las universidades de Leipzig, Berlín y Marburgo. En esta última conoce a los neokantianos H. Cohen y P. Natorp, a quienes considera siempre sus maestros.

En el ambiente filosófico de Marburgo predominaba el neokantismo, es decir, "la doctrina filosófica que postulaba la vuelta a Kant como modo de superar los callejones sin salida a que había llegado la filosofía idealista alemana de la mano de Hegel y sus discípulos"'. Ortega se sentirá siempre deudor de Kant y de los neokantianos, pero no abandona el espíritu crítico frente a ellos. Al respecto llegará a decir: "Durante diez años he vivido en el mundo del pensamiento kantiano. Lo he respirado como una atmósfera, fue a la vez mi casa y mi prisión"2. A su regreso de Alemania, en 1910, gana la cátedra de Metafísica en la Universidad de Madrid. Comienza, pues, su actividad universitaria como catedrático, sin haber publicado ningún libro de filosofía. En ese mismo año inicia su vida pública. En 1914 funda la "Liga de Educación Política Española" —con la que intentará llevar a cabo sus proyectos regeneracionistas- y escribe Meditaciones del Quijote, su primer libro. En 1916 es cofundador del diario El Sol y en 1923 (el mismo año en que inicia la dictadura de Primo de Rivera) funda la Revista de Occidente.

Su enfrentamiento con el régimen lo lleva a renunciar a su cátedra universitaria y a continuar sus clases en un teatro, lo cual lo convierte en uno de los primeros filósofos españoles en explicar su concepto de filosofía al gran público. Se trata de las clases que más tarde se publicarán bajo el título ¿Qué es filosofía? "En 1930, coincidiendo con la 'dictablanda' del general Berenguer [...] Ortega recupera su cátedra y su participación en la política activa va en aumento, hasta el punto de convertirse en el centro de un grupo de intelectuales que propugnan el advenimiento de la II República Española. Así, en 1931, llegada la República, funda [...] la Agrupación al Servicio de la República. Gracias a la Agrupación es elegido diputado de las Cortes Constituyentes por la provincia de León; pero, una vez más, se repite la paradoja de todo filósofo 'metido en política', pues en las Cortes se le oye y no se le sigue. La desilusión que le produce la vida de diputado lo lleva pronto a retirarse de la política activa y a disolver la Agrupación"3. Ortega retorna a la vida académica. En 1934 publica En torno a Galileo y en 1935 recibe un homenaje de la universidad y publica La historia como sistema. Para entonces "ya es la figura más sobresaliente del panorama filosófico español del momento"4. 
El inicio de la guerra civil española, en 1936, lleva a Ortega al autoexilio. Viaja a Francia, a Holanda y a Argentina, hasta que en 1942 fija su residencia en Portugal, en donde escribe Origen y epílogo de la filosofia. En 1945, terminada la II Guerra Mundial, Ortega vuelve a España, "pero en los diez años que tardará en llegarle la muerte, su actividad pública queda reducida al mínimo dadas las circunstancias políticas españolas"s. En 1946 se empiezan a publicar sus Obras Completas. En 1948, junto con un grupo de discípulos, funda el Instituto de Humanidades en el que de nuevo ejerce su magisterio ante el público, fuera de las aulas universitarias. Sin lograr sentirse a gusto en su propio país, Ortega viaja nuevamente a Alemania en 1950. Allí mantiene un debate filosófico con M. Heidegger acerca del hombre y su lenguaje. En 1955 regresa definitivamente a España, en donde muere de cáncer gástrico el 18 de octubre.

Quizá el dato más revelador del significado filosófico y humano de la muerte de Ortega lo proporcione el hecho de que, con motivo de su muerte, otro gran filósofo español, pero de vida y obras tan distintas de las de Ortega, X. Zubiri, escribió uno de sus raros artículos periodísticos. Precisamente él, a quien la prensa rogaba continuamente su colaboración sin recibirla, pedía ahora recordar la muerte de su maestro y compañero. De este modo, el 19 de octubre de 1955, aparecía en $A B C$ el artículo de Zubiri titulado 'Ortega metafísico', en el que se celebra la obra del maestro con, entre otras expresiones, la siguiente:

En el bracear denodado con la verdad de la vida y de las cosas, Ortega nos enseñó in vivo la radicalidad con que han de librarse, cara a la verdad, las grandes batallas de la filosofía. Es lo que permanentemente nos une a su espíritu con plena admiración, profundo respeto e íntimo cariñon.

Antes de terminar este breve bosquejo biográfico, conviene mencionar a los interlocutores filosóficos de Ortega y situar en su contexto la obra que comentaremos a continuación. Vayamos a lo primero. En lo que respecta a los clásicos, el interés de Ortega va a decantarse hacia dos etapas bien definidas de la historia del saber filosófico: "la filosofía griega y la filosofía continental europea que, partiendo de Descartes, llega hasta sus maestros de Marburgo"7. La filosofía medieval y la filosofía anglosajona son, pues, soslayadas por nuestro autor. En relación a la filosofía alemana contemporánea, "junto con la influencia principalísima de Natorp y Cohen - al grado de haber sido acusado de plagiar a este último-, se han conocido siempre otras influencias importantes, tales como Nietzsche, Husserl, Dilthey, Scheler y, al final de su vida, Heidegger"y. Esto sin mencionar a otros pensadores alemanes menos reconocidos, cuya influencia ha sido detallada en estudios exhaustivos sobre Ortega.

Sobre lo segundo, hay que aclarar que Unas lecciones de metafísica no fue concebido originalmente como un texto por publicar, sino que fue el producto de los cursos universitarios que Ortega impartió entre 1932 y 1933. Publicada póstumamente, en 1966, esta obra constituye, junto con ¿Qué es filosofia?, una pieza 
fundamental dentro la actividad filosófica de Ortega. En ellas, el autor explaya abiertamente su doctrina; ellas son expresión de su -injustificadamente cuestionada - originalidad filosófica. La renuencia de Ortega a publicar en vida estos textos obedeció a su temor a ser mal interpretado. "En la cátedra, ante personas que habian ido a oír hablar de filosofía, sobre todo estudiantes, se sentía confiado; además, estaba él presente, aclarando con la palabra viva, con el gesto, lo que verdaderamente quería decir"'. Y lo que verdaderamente quería decir, era, en principio, que había llegado el momento de superar el idealismo y escalar un peldaño más en el camino de la conquista de la verdad filosófica.

La superación del idealismo es la gran tarea intelectual, la alta misión histórica de nuestra época, el 'tema de nuestro tiempo'"1".

Vamos más allá del idealismo, por tanto, lo dejamos a nuestra espalda como un camino ya hecho, como una ciudad en que hemos ya vivido y que nos llevamos para siempre posada en el alma. Nos llevamos el idealismo, es decir, lo conservamos. Era un peldaño en la subida intelectual: ahora ponemos el pie en otro que está encima del idealismo y no debajo de él".

Del diagnóstico del idealismo como enfermedad de la modernidad y - sobre todo- de la solución que Ortega plantea frente a él, versan las lecciones que comentaremos en los apartados siguientes.

\section{La filosofía primera de Ortega y Gasset}

En este apartado pretendemos dar cuenta de las tesis básicas que Ortega defiende en sus Lecciones de metafísica. El objetivo es que quede claro por qué esta obra del autor puede considerarse una filosofia primera - término que él no utiliza, dicho sea de paso-. La claridad que caracteriza al discurso orteguiano hace innecesaria una interpretación extensa. Baste decir que esta disertación se enmarca dentro del objetivo fenomenológico de encontrár una verdad radical, indubitable, accesible para cualquiera y capaz de fundamentar a las demás verdades; es decir, de encontrar una verdad primera. En ese sentido, podemos afirmar que este texto es un texto de filosofía primera; es el texto en el que Ortega persigue esa verdad primera y fundante. Con ello pretende situarse en un plano más radical que sus antecesores filosóficos realistas e idealistas, superando a Husserl y a Heidegger inclusive.

Para lograr nuestro propósito nos limitaremos a explicar tres cosas: qué entiende Ortega por metafísica; en dónde ve las insuficiencias del realismo y del idealismo en sus respectivas propuestas de verdad primera, y cuál es su solución ante las limitaciones de aquellos planteamientos. Conscientes de que muchas de las tesis que sostiene nuestro autor en el texto en cuestión quedarán de lado en este trabajo, restringimos nuestro campo a estos tres puntos, presumiendo que es en ellos en los que Ortega expresa su originalidad filosófica y en donde su re- 
flexión —que es sumamente extensa y diversa - alcanza el máximo nivel de trascendencia para la filosofía.

\subsection{La metafisica como búsqueda de orientación radical}

La condición esencial del ser humano, nos dirá Ortega, es su radical desorientación. No es que de vez en cuando ocurra un despiste o que en ciertos momentos de desesperación nos encontremos sin saber qué hacer. Es que el hombre consiste sustantivamente en sentirse perdido. La vida es radical desorientación. Pero no vivimos perdidos, podríamos replicarle; todo lo contrario, sabemos que nuestra casa se encuentra ubicada en determinada dirección, que debemos levantarnos a tal hora para ir al trabajo, que pertenecemos al país tal, que somos terrícolas, que ocupamos un lugar en el universo... iY acaso todo eso es prueba inquebrantable de nuestra orientación?, preguntaría él. Pues no lo parece, sería su respuesta. Porque bien pensado el asunto, todas esas pequeñas seguridades sobre las cuales construimos nuestra vida son heredadas, son seguridades que los demás nos han legado y que hemos aceptado sin más. La dirección de nuestra casa, las horas que se miden con el reloj, el territorio al que llamamos país, el planeta tierra y el universo son cosas en las que creemos porque los demás nos han enseñado a creer, pero no porque hayamos llegado a ellas por nosotros mismos, no nos constan a nosotros.

Para que algo nos conste es necesario que antes nos hayamos hecho cuestión de él, que se haya convertido en problema para nosotros. Y asumir un problema implica sentir desorientación. La desorientación es la auténtica situación del ser humano. Se vive auténticamente cuando se reconoce esa desorientación radical, cuando el mundo se nos presenta siempre como problema. Pero cuando vivimos de acuerdo a las orientaciones que los demás nos ofrecen, actuando según las convicciones de la gente, de la sociedad, entonces nuestra vida es ficticia porque camina sobre seguridades falsas, seguridades que no hemos conquistado por nosotros mismos. Lo que en esa forma ficticia de vivir ocurre es la suplantación de nuestra efectiva personalidad por un pseudo-yo proveniente del contorno social; es la entrega ciega a ese repertorio de convicciones ajenas que obedece al deseo de huir de la angustia que nos produce la desorientación radical en la que estamos insertos. Huimos del "auténtico sí mismo" para correr a refugiarnos en los brazos de la "personalidad convencional" que nos cobija ${ }^{12}$. Pues bien, la metafísica es el intento de dar respuesta a ese extrañamiento en el que la vida consiste, es el intento de obtener orientación frente al caos mundanal que nos desorienta radicalmente. Por eso todos los seres humanos, consciente o inconscientemente, hacemos metafísica. Así es, todos sin excepción. La metafísica es algo que el hombre hace, es una más entre las muchas cosas que hace; pero comporta una especial singularidad: es el hacer que busca orientación para todos los demás haceres. 
Con esta definición pretende Ortega radicalizar los alcances de la metafísica, dar un paso más allá en el camino de la historia de la filosofía. A lo largo de los mil quinientos años en los que esa historia ha transcurrido - afirma-, la metafísica se ha hecho cargo de dos problemas fundamentales: el del ser y el del saber. Para planteárselos se ha preguntado qué son las cosas (preocupación del horizonte clásico) y cuáles son las posibilidades del conocimiento (inquietud del horizonte moderno). Esto significa que la metafísica ha creído que para orientarse el hombre necesita "saber lo que las cosas son" o "conocerlas". La metafísica sería, entonces, el "saber radical". Lo que no se logra advertir con esta denominación es que se está dando por supuesto algo que se halla muy lejos de haber hallado una respuesta definitiva. Antes de averiguar qué son las cosas, ¿no habría que preguntarse qué es el ser? Y, asimismo, antes de preguntarse por los límites y posibilidades del conocimiento, ¿no habría que indagar en qué consiste elconocer? No se puede afirmar que saber es orientarse porque no se sabe a ciencia cierta qué es saber. Este es el descubrimiento que ubica a Ortega en un ámbito más radical que el de sus antecesores. "La idea de orientación —nos dirá- es más radical, más honda y previa que la idea de saber y no viceversa... la orientación no es un saber, sino al revés, el saber es una orientación"13.

Adelantándonos en algo de lo que profundizaremos más adelante, hay que decir que para Ortega la vida consiste en un yo y una circunstancia, siempre en mutua implicación. Yo tengo que hacer permanentemente mi vida, tengo que "habérmelas" con mi circunstancia. En lo que haga se juega lo que será de mí, lo que hago constituye lo que será mi ser. "El 'ser yo ahí' que es la vida, me lo encuentro, pues, como una tarea, como un problema que necesito resolver. Tengo, pues, que habérmelas con el 'ahi' y 'conmigo'. Para ello necesito organizar mi hacer, y para organizarlo necesito orientarme en el ahí de la circunstancia. Si no, no puedo dar ni un paso. ¿Por qué lo voy a dar en una dirección mejor que en otra? Más aún: ¿por qué no renunciar a todo hacer y dejarme morir?”|4. Dado que la existencia humana es radical desorientación, es un constante no saber qué hacer, el hombre no puede vivir sin buscar orientarse, sin interpretar sus actos, sin justificar su acción. "La vida humana es, pues, a un tiempo delito, reo y juez"'s.

Para orientarse, el ser humano traza un plan, planea su modo de habérselas con cierta cosa. Pero eso implica que conoce el ser de la cosa, que tiene un esquema de lo que esa cosa es. Ahora bien, no se puede tener un esquema de una cosa sin tener un esquema de las demás cosas que se relacionan con ella; necesita un plano de todo el conjunto. "Este plano de todas las cosas - nos dice Ortega - es el mundo y la orientación radical que él proporciona es la metafísica"'t. Esto precisa aún más la tesis de que la metafísica es un hacer constitutivo del ser humano. Vivimos haciendo metafísica. Somos metafísicos por naturaleza. "La metafísica no es una ciencia; es construcción del Mundo, y eso, construir mundo con la circunstancia, es la vida humana. El Mundo, el Universo, no le es dado al hombre: le es dada la circunstancia con su innumerable contenido. Pero 
la circunstancia y todo en ella es, por sí, puro problema... El puro problema es la absoluta inseguridad que nos obliga a fabricamos una seguridad. La interpretación que damos a la circunstancia, en la medida que nos conviene, que la creemos, nos hace estar seguros, nos salva. Y como el mundo o universo no es sino interpretación, tendremos que el mundo es la seguridad en que el hombre logra estar. Mundo es aquello de que estamos seguros"17.

Esta búsqueda radical de orientación tiene requisitos. No cualquier cosa puede ser "buena metafísica". En primer lugar, es necesario que a las tesis metafísicas el metafísico acceda por sí mismo, no valen las opiniones de otros que no estén radicalmente justificadas. Así, mientras el científico puede hacer su ciencia en comunidad, puede apropiarse de las opiniones de los otros si le son útiles, el metafísico está obligado a permanecer solo. "Metafísica es soledad"'ا8. "Nadie, por excelente que sea su voluntad, puede darnos hechas nuestras convicciones. Tenemos que convencernos a nosotros mismos"19. En segundo lugar, las tesis metafísicas buscan absolutez: han de ser tesis que se sostengan por sí solas, que no necesiten de otras tesis para ser válidas. Las otras tesis han de poder sostenerse sobre estas tesis primeras, nucleares. A hallar estas tesis primigenias dedicaron sus mejores esfuerzos el realismo y el idealismo. A continuación veremos como explora Ortega estos horizontes y en donde encuentra sus insuficiencias.

\subsection{Las insuficiencias del realismo y del idealismo}

La tesis realista, lo que el realismo considera como verdad primera, como verdad sobre la cual descansan todas las demás, es ésta: lo verdadero es el mundo. El realismo afirma que aquello de lo que no puedo dudar es de las cosas que se me presentan, de lo que hay. Las cosas están ahí, en y por sí mismas, independientemente de sí yo estoy o no para sentirlas. Yo soy una cosa más entre las cosas del mundo y así como yo existo independientemente de las cosas, ellas existen al margen de mí. Tan obvia parece ser esta tesis que cuando queremos afirmar que algo verdaderamente es decimos que es realidad". "Son realidad las cosas — nos dice el realismo, en la exposición de Ortega— porque están ahí en sí y por sí, puestas por sí mismas, sosteniéndose a sí mismas en la existencia"21. Y esto vale tanto para una piedra como para mí mismo, tanto para el sol como para mi brazo.

El problema del realismo es que su confianza ingenua en las cosas del mundo le impide darse cuenta de que para que haya cosas es preciso que haya un yo que las vea, que las oiga, que las toque, en definitiva, que las sienta y que se de cuenta de ellas. La afirmación de la realidad de las cosas con independencia del yo es cuestionable, se mueve en arena movediza. Porque, ¿cómo garantizar que cuando no hay yo hay mundo? No hay modo de estar absolutamente seguros, más bien hay que ponerlo en cuestión. "La realidad del mundo sólo resulta indubitable cuando además de él estoy yo viéndolo, tocándolo, y pensando que 
está ahí — precisa Ortega - Depende pues, la seguridad de su realidad, de mi realidad"22. Es justamente lo que va a sostener el idealismo en rechazo al realismo. Las cosas que hay en el mundo no pueden ser la realidad radical porque su realidad fuera del yo es dudosa. De lo único que podemos estar seguros por completo es de que las cosas están ahí ante mí, en mi pensamiento. O, en otras palabras, sólo puedo constatar la realidad de las cosas mientras ellas me sean presentes, mientras estén existiendo para mí. Eso significa que lo real, lo indubitable es mi pensar las cosas y no ellas por sí mismas. Así, el idealismo concede un momento de verdad al realismo: las cosas aparecen ante el yo, autónomamente; pero incluye lo que el realismo había excluido: mi pensar. No hay cosa sin mi pensar la cosa. Afirmar la realidad del mundo implica afirmar la realidad de un pensamiento que sostiene esa afirmación ${ }^{23}$.

No obstante, la tesis idealista, si bien supera al realismo, encuentra pronto una dificultad. Asegura como realidad radical al pensamiento, pero la naturaleza del pensamiento es distinta a la naturaleza de las cosas. "Cuando éste [el idealismo] me dice que la realidad de una cosa, la firme, la segura es que yo la pienso y que, por tanto, las cosas son pensamientos míos, nos encontramos por lo pronto con que no sabemos lo que quiere decir. Porque [por ejemplo] la pared es blanca y de seis metros, pero el pensamiento de pared, mi ver la pared o tener conciencia de ella no es blanco ni de un milímetro. Para que la realidad pared se convierta realidad pensamiento tiene, pues, que dejar de ser pared. Y, si en vez de la pared, tomamos un ejemplo más amplio, el 'fuera' en que la pared está, el espacio, tendremos: que al ser el espacio pensamiento deja él de ser espacial y un fuera, para convertirse en inespacial y un dentro de mîn'. El idealismo mismo es consciente de esta dificultad. Advierte lo problemático de explicar cómo es que el pensamiento, siendo inespacial e inextenso, puede dar cuenta y, más aún, ser la verdad última de las cosas, siendo estas espaciales y extensas.

"Al llegar aquí tenemos que seguir impertérritos obligando al idealista para que precise más su tesis. Por eso le preguntamos: ¿qué hay en el universo cuando sólo hay conciencia, pensamiento? Y él nos responde: hay un sujeto que piensa o se da cuenta y que no consiste sino en eso... Tanto vale, pues, decir que sólo hay pensamiento o conciencia como decir que no hay cosas, puesto que haberlas significa ahora haber el pensamiento de ella (sic). Esto es el auténtico idealismo"25. Retomando el ejemplo de la alucinación que gusta al idealismo, Ortega encontrará justamente la debilidad de su tesis, según la cual lo verdaderamente real es el sujeto. Un idealista sostendrá que, sin importar si lo percibido es real o es un alucinación, lo incuestionable es que existe un sujeto para el que eso real o alucinado se presenta. Supongamos, ejemplificará Ortega, que alucinamos con un toro furioso y que poco después nos percatamos de que se trataba de una alucinación. En principio, lo que pasó durante la alucinación era que nos encontrábamos nosotros aterrados ante el toro y se encontraba el toro aterrándonos. "Tan hay lo uno - el sujeto-, como la cosa —el toro- y no hay más lo 
uno que lo otro"2h. Luego caigo en la cuenta de que se trataba de una alucinación. En este segundo momento lo que hay es un yo y el recuerdo de mi alucinación. Ahora, ¿esto anula la vívida experiencia que tuve del toro? No. Tan real fue la alucinación, como real es en este momento segundo en que la rememoro. "¿Quién me asegura que no es ahora, al estar convencido de que padecí una alucinaciọ́n cuando efectivamente la padezco?"27.

Esto no significa nada menos que la tesis idealista es insostenible, porque cuando analizo exactamente lo que hay advierto que ahí no está presente mi pensamiento. Estoy presente yo - por eso no se trata de volver al realismo-, pero en mi vivencia de la cosa no está presente mi conciencia de ella. "El pensamiento que pienso, no lo hay, puesto que mientras lo pienso no existe para mí. Es preciso que deje de ejecutarlo, esto es, de estarlo pensando y desde otro nuevo lo convierta en objeto para mi"28. Por eso es inadecuado llamar pensamiento a eso que hago cuando presencio algo, cuando estoy viviendo la presencia de algo. Esa presencialidad es ejecutiva, es ejecutividad, es un puro hacer en el que el yo está presente en la misma medida que la cosa. Para que pueda haber pensamiento es necesario pasar a un momento segundo, abandonar la ejecutividad y luego intentar regresar a ella. "Cuando sólo hay pensamiento no hay efectivamente lo en él pensado. Cuando sólo hay mi ver esa pared, no hay pared"2y. Pensar es, pues, algo secundario respecto de la ejecutividad. Por eso el pensamiento no puede ser la verdad primera, antes de pensar ejecutamos.

Ahora detengámonos un poco en la crítica que hace Ortega a Descartes, padre del idealismo moderno. La genialidad cartesiana consiste en haber descubierto que la existencia de las cosas fuera de mí era problemática, dudosa y que, por tanto, la única certeza a la que puedo asirme es a mi dudar de las cosas. En mi duda, tanto yo como el mundo son absolutamente con una inmediatez indubitable. "Si creo ver veo como si creo dudar dudo"3.". Hasta aquí, Descartes es imbatible. Los problemas empiezan cuando da el salto hasta el pensamiento, cuando identifica ese ser las cosas para mi con ser las cosas para un sujeto pensante. Tal salto traiciona la primera conquista y la pretensión de mantenerse en lo indubitable. Al interponer la hipótesis sujeto, Descartes y el idealismo en general niegan la realidad del objeto, de la cosa y ya no dan cuenta fiel de lo que hay. Lo que hay es yo y cosa, en igualdad condición de inmediatez. Cuando pienso ya no hay cosa, entonces ya no hay inmediatez. "La cosa, en cuanto pensada, no necesita existir"31.

Por extraño que parezca, lo que llevó al idealismo a traicionar su propio punto de partida fue un impulso realista. Habíamos dicho que, para el realismo, las cosas existían por sí mismas, tenían autonomía respecto del yo. Pues bien, el idealismo realiza la operación inversa, pero animado por el mismo espíritu. Dirá: lo que existe es el sujeto por sí mismo, sosteniéndose a sí mismo, absoluto respecto de las cosas. No se atreve el idealista a quedarse en la pura inmediatez 
y necesita declarar la independencia de algo: del sujeto. "Y, sin embargo, es de sobra evidente que yo no encuentro la pared en mí sino fuera de mí, ante mí, todavía con más claridad que me encuentro a mí mismo o, por lo menos, con la misma claridad. Y viceversa, jamás me encuentro sólo conmigo, sino que siempre que me hallo resulta que estoy con algo que no soy yo, frente a mí"3:2. Esta constatación "nos obliga a buscar un concepto más adecuado y un nombre para esa realidad radical y absoluta que es lo inmediato"3.3. En el nombre y el concepto que propone Ortega ahondaremos en el siguiente sub-apartado.

\section{Vida, yo y circunstancia}

Frente a lo insatisfactorio del punto de partida idealista, Ortega propone como tesis primera a la vida. La vida, como condición de posibilidad de todo lo demás, como situación radical del hombre, es la verdad indubitable. Antes que hablar de ser o de saber, de ciencia o de teoría hay que reparar en la vida. La vida es el lugar en donde estamos instalados y desde el cual hacemos todo lo demás. Todo hacer es un vivir. "Yo no sé si eso que llamo mi vida es importante -dice Ortega-, pero sí parece que, importante o no, está ahí antes que todo lo demás, incluso antes que Dios porque todo lo demás, incluso Dios, tiene que darse y ser para mí dentro de mi vida" ${ }^{34}$. Cuando Ortega asegura que intenta "tomar los problemas filosóficos desde un estrato más hondo del que han sólido ser atacados"35 se refiere a que no quiere dar por sentados el ser y el saber, como si ya se pudiera dar cuenta cabal de ellos. Para lograr instalarse en ese estrato, es preciso quedarse en el mero análisis de esta verdad primigenia que es la vida, evitando los saltos teóricos que hicieran realistas e idealistas. Eso nos sitúa en un ámbito pre-metafísico, en la antesala de toda Metafísica.

Para llevar a cabo este análisis, Ortega recurre a la descripción de la vida desde sus rasgos más "periféricos" hasta los que le son esenciales. Siguiendo este método descubre que la vida posee tres atributos: (1) es una presencia inmediata, (2) es circunstancial, y (3) es intrínseca decisividad. Veamos en qué consiste cada uno. Lo primero que nos dice Ortega sobre la vida es que vida es "de todas las cosas la más próxima a cada cual"3.36, es todo lo que somos y lo que hacemos, es "lo que nos pasa". Y lo que nos pasa siempre es un presente; el pasado y el futuro sólo tienen realidad en el ahora, "la vida es siempre un ahora y consiste en lo que ahora es... En este sentido, la vida es pura actualidad, es puntual, es un punto -l presente-, que contiene todo nuestro pasado y todo nuestro porvenir"37. Bueno, pues esa actualidad en la que consiste la vida tiene la peculiar característica de ser algo de lo que nos damos cuenta. "Vivir es esa realidad extraña, única que tiene el privilegio de existir para sí misma. Todo vivir es vivirse, sentirse vivir, saberse existiendo; donde saber no implica conocimiento intelectual ni sabiduría especial ninguna, sino que es esa sorprendente presencia que su vida tiene para cada cual: sin ese saberse, sin ese darse cuenta, el dolor de muelas no nos dolería"38. 
Pero esa presencia no implica un cuerpo - he aquí la refutación de Ortega a Merleau Ponty- La corporalidad llega tarde a este momento primigenio que estamos queriendo describir aquí. Lo propio de la vida es que es "nuestra" vida, es que podemos tener un sentido de posesión sobre ella. "Al percibirnos y sentirnos, tomamos posesión de nosotros y este hallarse siempre en posesión de sí mismo, este asistir perpetuo y radical a cuanto hacemos y somos, diferencia el vivir de todo lo demás"39. Poseo mi vida porque me es transparente, porque es presente ante mí y esto es anterior a cualquier consideración sobre el cuerpo. El "mí" no es cuerpo, sino situación. Vivir es "encontrarse a sí mismo en el mundo y ocupado en las cosas y seres del mundo" "4l. Así, pues, "lo importante no es que las cosas sean o no cuerpos sino que nos afectan, nos interesan, nos acarician, nos amenazan o nos atormentan... Mundo es sensu stricto lo que nos afecta. Y vivir es hallarse cada cual a sí mismo en un ámbito de temas, de asuntos que le afectan" ${ }^{41}$.

Profundizando en el análisis, Ortega introduce una distinción imprescindible en su filosofía; es la distinción entre el "contar con" y el "reparar en". En la vida contamos todo el tiempo con muchas cosas, pero no somos conscientes de ellas. Contamos, por ejemplo, con nuestros pies para caminar, pero no pensamos a cada paso en nuestros pies, no reparamos en ellos. Considerado desde esta constatación, el problema del idealismo, su gran error, es haber creído que lo más inmediato, la verdad más obvia y transparente, es el "reparar en" las cosas. El idealismo no logró advertir que antes de reparar en ellas, es preciso "contar con" ellas. Ortega lo explica así: "mi vida y todo en ella me es preevidente, me consta o cuento con ello en forma tal que me es siempre posible convertir este 'contar con' en efectivo 'reparar en', en efectiva evidencia. Lo mismo podríamos decir que la vida es pre-consciente o que es pre-sabida. Por eso luego, el efectivo saberla es un 'caer en ello', un encontrar lo que ya teníamos, pero lo teníamos cubierto"42.

Aclarado esto podemos pasar a describir el segundo atributo que Ortega encuentra en el análisis de la vida: la circunstancialidad. El "mí" del que hablábamos está siempre en una circunstancia tal, entre unas cosas con las que tiene que habérselas. "No nos damos cuenta primero de nosotros y luego del contorno, sino que vivir es, desde luego, en su propia raiz, hallarse frente al mundo, con el mundo, dentro del mundo, sumergido en su tráfago, en sus problemas, en su trama azarosa. Pero también, viceversa: ese mundo al componerse sólo de lo que nos afecta a cada cual es inseparable de nosotros"4.3. No es sólo que cayendo en la cuenta de mi situación haya advertido que hay un yo, un 'mí' desde el cual vivo y siento la vida, es que ese yo está siempre envuelto entre las cosas del mundo, está siempre en una circunstancia. "Siempre que me encuentre me encontraré dentro de otra cosa, de la cual, por lo menos, puedo sin duda asegurar que será otra cosa que yo... El hombre al encontrarse no se encuentra en sí y por sí, aparte y solo, sino al revés, se encuentra siempre en otra cosa, dentro de otra 
cosa... Se encuentra rodeado de lo que no es él, se encuentra en un contorno, en una circun-stancia, en un paisaje $e^{44^{*}}$.

En esta descripción hemos enumerado, en primer lugar, la evidencia del yo, pero lo cierto es que tan ineludible es a nuestra vida el contorno que en lo primero en que reparamos, cuando nos interesa hacer conciencia sobre algo, es en el mundo, en las cosas que no son 'yo'. "Nuestra vida, por sí, consiste en estar nosotros consignados al mundo... la vida es inseparablemente y al mismo tiempo, sin que lo uno sea primero y lo otro después, contar conmigo y contar con el mundo. Sólo cuando se trata de la conciencia, del reparar en, es cuando lo uno es antes y lo otro después" ${ }^{35}$. Hacerme consciente de mí implica siempre un esfuerzo por separarme del mundo, por abstraerme de las cosas y de las personas con las que permanentemente tengo que habérmelas. Ahora bien, mi 'estar' en el mundo es un estar distinto al estar de, por ejemplo, una piedra. Yo no estoy en el mundo 'formando parte de él', no soy una cosa material más, sino que mi yo se caracteriza por su radical heterogeneidad. El 'mí' de mi vida es único, es otro que toda cosa e incluso que todo otro mí. Nadie puede ocupar el lugar de ese mí, por mucho que su vida sea similar a la mía.

De lo que sí puedo decir con certeza que formo parte es de mi vida. Yo y circunstancia son partes de la verdad primera que es vivir. "Yo no soy más que un ingrediente de mi vida: el otro es la circunstancia o mundo. Mi vida, pues, contiene ambos dentro de sí, pero ella es una realidad distinta de [ambos]... La realidad de mi yo es, pues, secundaria a la realidad integral que es mi vida; encuentro aquélla - la de mi yo- en ésta, en la realidad vital"46. En este punto cabe enfatizar sobre el carácter del 'estar' que en la vida conecta al yo y a la circunstancia. Estar en el mundo no significa pensar el mundo. Yo puedo estar en una habitación haciendo infinidad de cosas que no tengan nada que ver con pensar en la habitación y, sin embargo, continuaré estando en ella. El pensar es una de las tantas cosas - todo lo peculiar que se quiera, pero una más entre las demás - que puedo hacer estando en una circunstancia.

Además, para pensar es preciso haber perdido ya a la cosa pensada. El pensamiento llega tarde a la vivencia efectiva de una situación, es siempre un momento segundo. "Saber es posesión del ser de una cosa, no de la cosa"47. Con esto tenemos que lo primero de una cosa cuando pensamos en ella es problema, cuestión, pregunta. El pensamiento es pura ignorancia. Sabemos que una cosa tiene ser, pero ignoramos cuál es. Las cosas se nos convierten en problema cuando nos resultan extrañas, cuando nos incomodan - la luz que deja de alumbrarnos, por ejemplo-. Es entonces cuando reparamos en ellas, cuando nos interrogamos acerca de ellas. Si nada nos incomodara, no tendríamos necesidad de reparar en las cosas, porque las sentiríamos como parte de nuestro propio yo. "Cada cosa en mi vida es, pues, originariamente un sistema o ecuación de comodidades e incomodidades. Cuando una cosa me es incómoda se me hace cues- 
tión: porque la necesito y no 'cuento con' ella, porque me falta. Las cosas, cuando faltan, empiezan a tener un ser. Por lo visto, el ser es lo que falta en nuestra vida, el enorme hueco o vacío de nuestra vida que el pensamiento, en un esfuerzo incesante, se afana en llenar"48.

Después de esta larga explicación ahondando en lo que es la circunstancia podemos llegar al fin al análisis del tercer atributo de la vida: la decisividad o versión al futuro. Somos arrojados al mundo, al ahora en que consiste nuestra circunstancia, sin previo aviso y sin haber dado nosotros nuestro consentimiento. Estamos simplemente puestos aquí. "Vivir es... encontrarse de pronto y sin saber cómo, caído, sumergido, proyectado en un mundo incanjeable... No nos hemos dado a nosotros la vida sino que nos la encontramos, justamente, al encontramos con nosotros. Un símil esclarecedor fuera el de alguien que dormido es llevado a los bastidores de un teatro y alli, de un empujón que lo despierta, es lanzado a las baterías, delante del público. Al hallarse, ¿qué es lo que halla este personaje? Pues se halla sumido en una situación difícil sin saber cómo ni por qué, en una peripecia; la situación difícil consiste en resolver de algún modo decoroso aquella exposición ante el público, que él no ha buscado, ni preparado ni previsto. No nos la han anunciado antes de llegar a ella —en su escenario, que es siempre uno concreto y determinado-, no nos han preparado"44.

Una gran paradoja de la vida es que nos es dada sin más, pero se nos presenta como problema, es nuestro problema, es el problema que constantemente tenemos que resolver. $Y$ en resolverlo consiste nuestra vida. Cada paso que damos, cada acto, es producto de una decisión nuestra, estamos obligados a decidir, la decisión es condición inexorable de nuestra vida. "Dicho de otro modo: vivimos sosteniéndonos en vilo a nosotros mismos, llevando en peso nuestra vida por entre las esquinas del mundo. $Y$ con esto no prejuzgamos si es triste o jovial nuestra existencia: sea lo uno o lo otro está constituida por una incesante forzosidad de resolver el problema de sí misma"s". Esto es lo que hace de la vida una radical apertura, una constante problematicidad. Estamos a cada instante obligados a elegir una posibilidad entre las múltiples que se nos ofrecen. "Nuestra vida es nuestro ser. Somos lo que ella sea y nada más; pero ese ser no está predeterminado, resuelto de antemano sino que necesitamos decidirlo nosotros, tenemos que decidir lo que vamos a ser, por ejemplo, lo que vamos a hacer al salir de aquí [del salón de clases]"si.

Y así llegamos a la segunda paradoja que nos interesa dejar consignada aquí: dado que "vivir es constantemente decidir lo que vamos a ser", el ser humano "consiste más que en lo que es, en lo que aún no es"52. De esto se trata la versión al futuro que mencionábamos. Vivimos vertidos hacia lo que vendrá, hacia lo que seremos o podremos ser. "La vida es una actividad que se ejerce hacia adelante, y el presente o el pasado se descubre después, en relación con el futuro" 5.3 . "El hombre comienza por ser su futuro, su porvenir"s4. Está claro que los hábitos 
hacen fácil esta decisividad ineherente a la vida, pero aún así estamos siempre ocupados en decidir nuestra siguiente ocupación, "esto es ocuparse por anticipado, es ocuparse antes de ocuparse, es... pre-ocuparse. La vida es preocupación"ss. Pero también es perplejidad. Como a cada instante estamos en la expectativa de lo que vendrá, en la incertidumbre del porvenir, permanecemos perplejos. Cada momento es una encrucijada que nos ofrece diferentes caminos. Del que elijamos dependerá lo que seremos, en nosotros recae la responsabilidad de nuestro propio ser.

Veamos el contundente resumen que hace Ortega acerca del repertorio de posibilidades con el que el ser humano cuenta para realizar su vida: "Ante este teclado de posibles quehaceres somos libres para preferir el uno al otro, pero el teclado, tomado en su totalidad, es fatal. Las circunstancias son el círculo de fatalidad que forma parte de esa realidad que llamamos vida... Dentro de la fatalidad de vuestra circunstancia sois libres; más aún, sois fatalmente libres porque no tenéis más remedio, queráis o no, que escoger vuestro destino en la holgura y al margen que os ofrece vuestra fatal circunstancia"5h.

\section{Ortega, entre Heidegger y Zubiri}

Tempranamente apareció en la obra de Ortega la frase que anunciaría su novedad filosófica: la famosa "yo soy yo y mi circunstancia" fue formulada por nuestro autor en su primer libro, Meditaciones del Quijote, en 1914. Para entonces, Ortega era heredero de Husserl; había asumido el propósito de quedarse en la mera descripción de los fenómenos, aceptando "su patencia absoluta como realidad primaria de cuyo análisis se ocuparía toda la filosofía que quiera ser verdaderamente radical"s7. A ese plano radical es a lo que Ortega denomina "vida individual, lo inmediato, circunstancia"5r. Aquí ya no es posible dar primacía al objeto sobre el sujeto o viceversa - como lo pretendió el idealismo-. Lo que hay es una "constitutiva vinculación" entre esos dos aspectos; a esa vinculación es a lo que la fenomenología llamó intencionalidad ${ }^{54}$. Por esto, y porque al defender la primariedad de la perspectiva —-como "ser definitivo del mundo" poniendo el énfasis en el sujeto y no en el objeto"1, puede verse en este primer Ortega a un auténtico fenomenólogo.

Lo que Ortega no aceptará de la fenomenología es que la mutua imbricación entre sujeto y objeto se funde en una conciencia, en un cogito ${ }^{\text {h2 }}$. Ante esta tesis, Ortega defenderá el carácter ejecutivo de la vida, el incesante devenir en el que vivir consiste ${ }^{\text {h3. }}$. La vida no es primariamente un pensamiento, un instante congelado, sino, por el contrario, un perpetuo fluir.

Pero el distanciamiento definitivo con Husserl vendrá a partir de la lectura de Ser y tiempo $o^{64}$, en $1927^{65}$. Con Heidegger descubrirá Ortega la posibilidad de un “ámbito de la imbricación entre ser y mundo anterior a toda distinción entre sujeto y objeto" 
como el Dasein, Ortega le dará una reformulación y lo llamará vida. "Hasta ¿Qué es filosofía? (1929) Ortega había ejecutado solamente la primera operación (el paso de la conciencia al viviente que la funda), pero no la segunda (la vida como realidad radical anterior tanto al mundo como al yo) [...] Esto es lo que Ortega realiza clara y temáticamente en ¿Qué es filosofía? Allí declara explícitamente que mientras para los antiguos ser significaba 'cosa' y para los modernos 'subjetividad', 'para nosotros significa "vivir"'. Pero aquí vida 'no soy yo solo, yo sujeto, sino que vivir es también mundo' [...] La vida como realidad radical asume así en Ortega un papel que, si bien es preanunciado en textos anteriores, solamente se puede entender a cabalidad desde el Dasein heideggeriano, pues solamente desde él se entiende su anterioridad no sólo respecto de la conciencia sino también respecto del sujeto viviente y del mundo"h7.

Heidegger abrió, pues, la vía de escape al intelectualismo, pero quedó preso de él al ubicar en el plano más radical la comprensión del sert. "Ni el ser es lo originario respecto al 'mero tener delate' ni la realidad del hombre se puede reducir a preguntar por la verdad [...] La vida humana, para Ortega, es fundamentalmente acción y no comprensión, ejecutividad y no desvelación" "ị". "Con esto queda situada la filosofía de Ortega, a la altura de 1929, en su nivel de madurez. Otros escritos posteriores van a confirmar, en lo fundamental, estos logros. En Lecciones de metafisica (1932), Ortega subraya que la vida no es solamente la persona ni tampoco el término objetivo de la misma, sino un momento radical previo, como repite también en En torno a Galileo. Desde aquí se concreta la crítica al intelectualismo: la dimensión fundamental de la vida no es la conciencia ni el pensar, sino el habérselas con una circunstancia para desde ella determinar lo que uno va a ser"7".

La ejecutividad permite a Ortega "poner un pie fuera de la fenomenología y del ámbito del sentido donde aún se mueve Heidegger"'1; es lo que le permite, en definitiva, terminar de salir del horizonte moderno. Es en esa ruta hacia un nuevo horizonte filosófico en la que se inscribe la filosofía primera de Zubiri. Las similitudes entre el punto de partida orteguiano y el zubiriano saltan a la vista; enfrentarse con textos de ambos evidencia diáfanamente la razón por la cual Zubiri se reconoce "hechura orteguina". Y justamente en honor a esa huella de Ortega que tan profundamente marca su obra, Zubiri se ve impelido a avanzar en el camino inaugurado por Ortega y a superarlo. Intentemos ver cómo. "Hemos visto como Ortega alcanza un concepto radical de vida como punto de partida de toda investigación filosófica y como ámbito originario del trato con aquellas realidades con las que simplemente contamos sin pensar en ellas o hacerlas conscientes, sean estas cosas o ideas. Ortega subraya repetidamente que la realidad radical, la ejecutividad o vida es antes que todo pensar y toda conciencia un mero 'contar con'"n?. 
"En el análisis de esa realidad radical [...] es donde abundará la filosofía zubiriana. Zubiri mostrará cómo el 'contar con' es el momento formalmente intelectivo de toda acción. En el punto de partida hay una unidad radical entre sentir (proceso accional) e inteligir accesible en el mero análisis de los actos humanos [...] Las dimensiones radicales de la vida del hombre en el mundo son el enfrentamiento con las cosas como realidad, y el habérselas con ellas como realidades (SH 568). De ese modo la realidad no quedará en una filosofía primera asimilada como en Ortega a su funcionalidad"73. Lo que esto significa es que, así como Heidegger superó en profundidad a Husserl y Ortega hizo lo mismo con Heidegger, Zubiri se detuvo más minuciosamente en el análisis de lo dado y encontró que hay algo más radical que la vida orteguiana. Antes que encontrar unas cosas con las que cuento y que me facilitan o dificultan la vida, antes que vivir, sufrir, anhelar o ser feliz en el mundo, lo otro se me presenta como real, las cosas en mi aprehensión aparecen reclamando suidad, reclamando ser de suyo, su carácter de en propio.

"La vida está constituida por un proceso sentiente cuya unidad jamás se rompre ni el animal humano ni en los demás". Lo que diferencia la vida humana de la animal es, para Ortega, la praxis o vida activa. La vida humana, a diferencia de la vida animal, no consiste simplemente en ocuparse de lo otro y de las cosas sino que puede ensimismarse para formarse ideas y así volver sobre el mundo y actuar sobre él conforme su propio plan. Pero, como señalará A. González, este concepto de acción o vida humana como síntesis de actividad y pensamiento, más que desprenderse de una filosofía primera que se atuviera al análisis del ámbito originario de la realidad radical, parece derivarse de una antropología filosófica que ha abandonado ya el nivel de radicalidad alcanzado en su noción de vida. La actividad para Ortega viene posibilitada por una interioridad desde la que el ser humano puede actuar sobre el mundo y las cosas. En Zubiri, en cambio, la diferencia entre el sentir el humano y el animal está en que en la acción humana hay aprehensión de realidad [...] Para Zubiri, la acción humana es activa no por ser producto de una vida ensimismable, sino por tener un momento de aprehensión de realidad, por tener una radical unidad en el hombre el sentir (acción) y el intelegir: 'No es que la vida me fuerce a inteligir, sino que la inteligencia por ser intelección sentiente, es la que me fuerza a vivir pensando' (IRA 37). La caracterización de lo propio de los actos humanos se alcanza sin salir del análisis de los actos mismos ${ }^{74}$.

Otra insuficiencia detectada por Zubiri en el análisis orteguiano es que el yo de Ortega, si bien ya no es un sujeto o una conciencia, continúa teniendo prioridad sobre la circunstancia, aunque se encuentre imbricado con ella. "La alteridad en Ortega dice siempre referencia a un mí o me primario. Zubiri, empero, muestra el papel de la alteridad en la génesis misma de la circunstancia y de la mismidad. La realidad fundamental no sería una relación entre yo y circunstancia, sino algo anterior a toda relación. Es justamente lo que Zubiri llama realidad 
como modo de alteridad. La alteridad es para Zubiri la raíz misma de toda circunstancia, de todo mundo y de toda mismidad [...] En esta alteridad radical se anudan los demás, las cosas y yo mismo, colocándose así Zubiri en un ámbito trascendental, el ámbito de la realidad primordial, donde el mí no tiene ningún privilegio sobre los demás. y sobre las cosas. El hecho radical del que parte Zubiri es la actualización de todas las realidades aprehendidas, incluida la propia, en un mismo plano, en la misma formalidad de realidad"75.

Aunque hay un último aspecto que analiza J. Corominas en su tesis doctoral sobre la insatisfacción de Zubiri con el punto de partida orteguiano, en esta aproximación nos quedaremos con estas tres críticas básicas: el desliz de Ortega desde el análisis de la verdad primera hacia una antropología filosófica, el privilegio del que continúa gozando el yo en la descripción orteguiana y el carácter secundario, hasta cierto punto accesorio, que Ortega da a la alteridad en la estructura de la acción humana.

\section{Conclusión}

Lo primero que se puede decir después de una aproximación medianamente desprejuiciada a la filosofía de Ortega es que las airadas polémicas entorno al talante filosófico de su obra, a su originalidad y, por ende, a su estatura como filósofo sólo pueden justificarse a la luz de los crudos acontecimientos políticos que caracterizaron a la España de su época. Ortega no fue sólo un filósofo en el sentido pleno del término, sino que su pensamiento tiene una importancia capital, tanto en el orbe filosófico ibero-americano contemporáneo, como en la historia de la filosofía en general.

Toda la polémica en torno a su persona y a su producción intelectual supone que Ortega se salió con la suya en su afán de comprometerse con la circunstancia. Sólo una persona fiel a ese compromiso puede generar tan. ácidos adversarios y tan aguerridos defensores. Pero también se salió con la suya nuestro autor en su pretensión de ser un pensador a carta cabal. Quizá la filosofía de Zubiri sea el mejor y más actual testimonio de la secuela que la honesta búsqueda de la verdad por parte de Ortega dejó en la filosofía y en la cultura occidental. De manera, pues, que Ortega se salió con la suya en su vida. La misma figura que sostuvo que la vida es un proyecto del cual hay que hacerse cargo, consiguió hacerse cargo de su propio proyecto existencial y cumplió con sus dos grandes objetivos. En ese sentido, no se puede menos que reconocer que Ortega fue -0 intentó serlo mientras pudo- consecuente.

También en el terreno filosófico Ortega cosechó grandes triunfos: la superación definitiva del idealismo, desde un ámbito más radical y superior a él y no desde un retroceso respecto suyo; la conquista de un nuevo rumbo para el bracear fenomenológico en busca de "las cosas mismas"; la creación de una jerga filosófica en lengua española, al alcance del gran público y no sólo de un selecto 
grupo de entendidos; la superación de Heidegger y con ello la posibilidad de darle una interpretación no antropológica ni existencialista a su obra; entre muchos otros que sin duda podrían citarse.

La lectura de la filosofía primera de Ortega a la luz del análisis de Zubiri, no puede menos que rebelar ciertas insuficiencias e imprecisiones importantes. Nada mejor para exaltar y dar el lugar que le corresponde al pensamiento ortegueano que cuestionarlo, interpelarlo, evidenciar su perfectibilidad, compretarlo. Ortega no es el tipo de filósofo que se aferra dogmáticamente a su obra, sino, por el contrario, es de los que están dispuestos a poner cualquier tesis en discusión. Hacerlo, siguiendo el mismo camino que él trazara, es el mejor tributo que Zubiri pudo haberle hecho. Del mismo modo, polemizar en torno a él debe ser considerado un honor para alguien cuyo castigo hubiera sido pasar desapercibido o provocar un indiferente silencio.

\section{Notas}

1. Chamizo Dominguez, P. J., Ortega y la cultura española, Madrid, 1985, p. 33.

2. Ortega citado en Chamizo Dominguez, ibíd., p. 34.

3. Cfr. Ibid., pp. 36-37.

4. Ibid., p. 37.

5. Ídem.

6. Ibid., p. 39.

7. Ibid., p. 48.

8. Ibid., p. 51.

9. Cfr. Marías, J., Ortega. Las trayectorias, Madrid, 1983, p. 298.

10. Ortega citado en Marías, J., ibid., pp. 299-300.

11. Ortega citado en Marias, J., ibid., p. 299.

12. Cfr. Ortega y Gasset, J., Unas lecciones de metafisica, México, 1998 (4² ed.), pp. 133 y 134.

13. Cfr. Ibid., pp. 131 y 132.

14. Ibid., p. 179.

15. Ibid., p. 179.

16. Ibid., p. 179.

17. Ibid., p. 180.

18. Cfr. Ibid., pp. 180 y 181.

19. Ibid., p. 181.

20. Aclaración importante por parte de Ortega: "Conste, pues, que en esta palabra van fundidos y confundidos dos significados diferentes: uno, el carácter de lo que última y définitivamente existe; otro, el modo de ser peculiar de las cosas externas". Ibid., pp. 186-187.

21. Ibid., p. 187.

22. Ibid., p. 187.

23. A modo de excursus, Ortega incluye en sus consideraciones sobre el realismo y el idealismo una reflexión que si bien no es de nuestra competencia estricta, puede ser de mucha relevancia para una filosofía social; de ahí que la incluyamos al margen. Se trata de su análisis sobre la "estructura que da a la vida la convicción realista", 
en contraposición a la vida que se estructura a partir de la convicción idealista. "En el realismo - sostiene nuestro autor- vivir es encontrarse desde luego en lo seguro, en la tierra firme del mundo. Necesita ir averiguando en su detalle cómo es ese mundo, las leyes de su conducta o ser. Pero sabe de antemano que hay en él esas leyes, que tiene un ser. En cambio, el idealista se encuentra con que le han quitado lo seguro, el mundo de debajo de los pies: se ha quedado sólo el sujeto como única realidad... No puede, en consecuencia apoyarse en nada porque no hay nada fuera de él... Este hombre tiene, en absoluto, que hacerse el mundo en que va a vivir; más aún, vivir se convierte para él en construir un mundo puesto que no lo hay; diriamos, tiene que sacarse el mundo de la cabeza, en vez de aprender lo que el mundo es adaptándose al que ya está ahí, como hace el realista. Para éste, vivir será conformarse al mundo, por tanto, conformarse con el Mundo. Realismo es conformismo. Mas para el idealista la cuestión estará en crear un mundo según las ideas, según nuestros pensamientos... es preciso hacer que lo que hay - las presuntas cosas — se adapten a nuestras ideas que son la auténtica realidad. Ahora bien, este es el espíritu anti-conformista, el espíritu revolucionario. El idealismo es por esencia revolucionario". Ibid., p. 188.

24. Ibid., p. 189.

25. Ibid., p. 191.

26. Cfr. Ibid., p. 191.

27. Ibid., p. 191.

28. Ibid., p. 192.

29. Ibid., p. 192.

30. Ibid., p. 194.

31. Ibid., p. 196.

32. Ibid., p. 197.

33. Ibid., p. 198.

34. Ibid., p. 134.

35. Ibid., p. 131.

36. Ibid., p. 134.

37. Ibid., p. 135.

38. Ibid., p. 136.

39. Ibid., p. 136.

40. Ibid., p. 136.

41. Ibid., p. 136 y 137.

42. Ibid., p. 143.

43. Ibid., p. 137.

44. Ibid., p. 147 y 148.

45. Ibld., p. 137.

46. Ibid., p. 156.

47. Ibid., p. 159.

48. Ibid., pp. 162 y 163.

49. Ibid., p. 137.

50. Ibid., p. 138.

51. fdem.

52. Ibid., p. 139.

53. Idem. 
54. Ibid., p. 163.

55. Ibid., p. 164.

56. Ibid., p. 165.

57. González, A., "El problema de la alteridad en Ortega", Realidad, 58, julio-agosto, 1997, p. 374.

58. Ídem.

59. Ídem.

60. Ídem.

61. Ibid., p. 375.

62. Ibid., pp. 374-375.

63. Ídem.

64. Ibid., p. 375.

65. Marias, J., op. cit., pp. 325 y ss.

66. González, A., op. cit., p. 376.

67. Ídem.

68. Ibid., p. 377.

69. Ídem.

70. Ídem.

71. Corominas, J., Ética primera. Aportación de X. Zubiri al debate ético contemporáneo, Tesis Doctoral, San Salvador, 1998, p. 223.

72. Ibid., p. 227.

73. Ídem.

74. Ibid., pp. 227-228.

75. Ibid., p. 228. 